\title{
Calculation of air change rates and post-aerosol pause times for a COVID-19 airway management enclosure
}

\author{
Andrew D. Milne, MD BEng MSc PEng (D) Matthew I. d'Entremont, BEng \\ MS PEng • J. Adam Law, MD
}

Received: 8 June 2020/Revised: 12 June 2020/Accepted: 13 June 2020/Published online: 25 June 2020

(c) Canadian Anesthesiologists' Society 2020

\section{To the Editor,}

Numerous enclosures have been developed to contain aerosols and reduce the risk of coronavirus disease (COVID-19) transmission to healthcare providers during airway management. These enclosures can function as a mechanical barrier to droplets and aerosols, but adding a filtered suction source may further reduce the exposure risk by evacuating the working space during airway management. Simulations with Glo-germ ${ }^{1}$ or smoke $^{2}$ have qualitatively assessed the use of suction to evacuate these enclosures, and particle counters have been utilized to quantify aerosol removal. ${ }^{3}$ The United States Centers for Disease Control and Prevention (CDC) recommends a minimum of 15 air changes per hour (ACH) for operating rooms and $12 \mathrm{ACH}$ for negative pressure rooms. It also specifies the times required to purge airborne contaminants from these rooms. ${ }^{4}$ At present, there are no standard ventilation requirements for COVID-19 containment enclosures and no studies have calculated the $\mathrm{ACH}$ or airborne contaminant removal times ${ }^{4}$ within such enclosures. We sought to quantify the flow rates induced

\footnotetext{
A. D. Milne, MD BEng MSc PEng ( $\varangle)$

Department of Anesthesia, Pain Management and Perioperative Medicine, Dalhousie University, Halifax, NS, Canada

e-mail: admilne@dal.ca
}

School of Biomedical Engineering, Dalhousie University, Halifax, NS, Canada

M. I. d'Entremont, BEng MS PEng

Nova Scotia Product Design and Development Centre, Dalhousie University, Halifax, NS, Canada

\section{J. Adam Law, MD}

Department of Anesthesia, Pain Management and Perioperative Medicine, Dalhousie University, Halifax, NS, Canada by application of suction to a COVID-19 airway management enclosure and used these measurements to calculate the $\mathrm{ACH}$ and theoretical times for airborne contaminant removal. ${ }^{4}$

A prototype enclosure was developed for airway management in COVID-19 patients (Figure). The enclosure was evacuated using a suction line connected to a filter and a manifold pipe. Measurements were taken to determine the flow rates delivered by common suction sources available in the operating room. Flow rate testing was performed using a Puritan Bennett PTS 2000 ventilator tester (Mallinckrodt Inc, St Louis, MO, USA) placed in line with each suction source. Standard anesthesia machine and surgical canister suction sources with their associated pressure regulators were tested first. The anesthesia and surgical suction sources were connected with surgical suction tubing $(7 \mathrm{~mm}$ diameter, $4.6 \mathrm{~m}$ long, Medline Industries Inc, Northfield, IL, USA) to the viral filter and manifold pipe. The second option tested was via direct attachment of the viral filter and manifold pipe to a $2.4 \mathrm{~m}$ long standard yellow medical vacuum hose and MEDVAC wall outlet suction (Amico Corp, Richmond Hill, ON, Canada).

The anesthesia machine and surgical suction sources delivered comparable flow rates in the range of 35-37 $\mathrm{L} \cdot \min ^{-1}$; whereas direct attachment to the MEDVAC suction hose delivered a flow of $118 \mathrm{~L} \cdot \mathrm{min}^{-1}$. Assuming nominal flow rates of 35 and $115 \mathrm{~L} \cdot \mathrm{min}^{-1}$, the calculated ACH values ${ }^{4}$ for our enclosure would be 10.6 and 34.8, respectively. The corresponding theoretical times for airborne contaminant removal at $99 \%$ and $99.9 \%$ efficiency $^{4}$ would be 26 and 39 min respectively for a flow rate of $35 \mathrm{~L} \cdot \mathrm{min}^{-1}$, or eight and $12 \mathrm{~min}$ respectively for a flow rate of $115 \mathrm{~L} \cdot \mathrm{min}^{-1}$. 


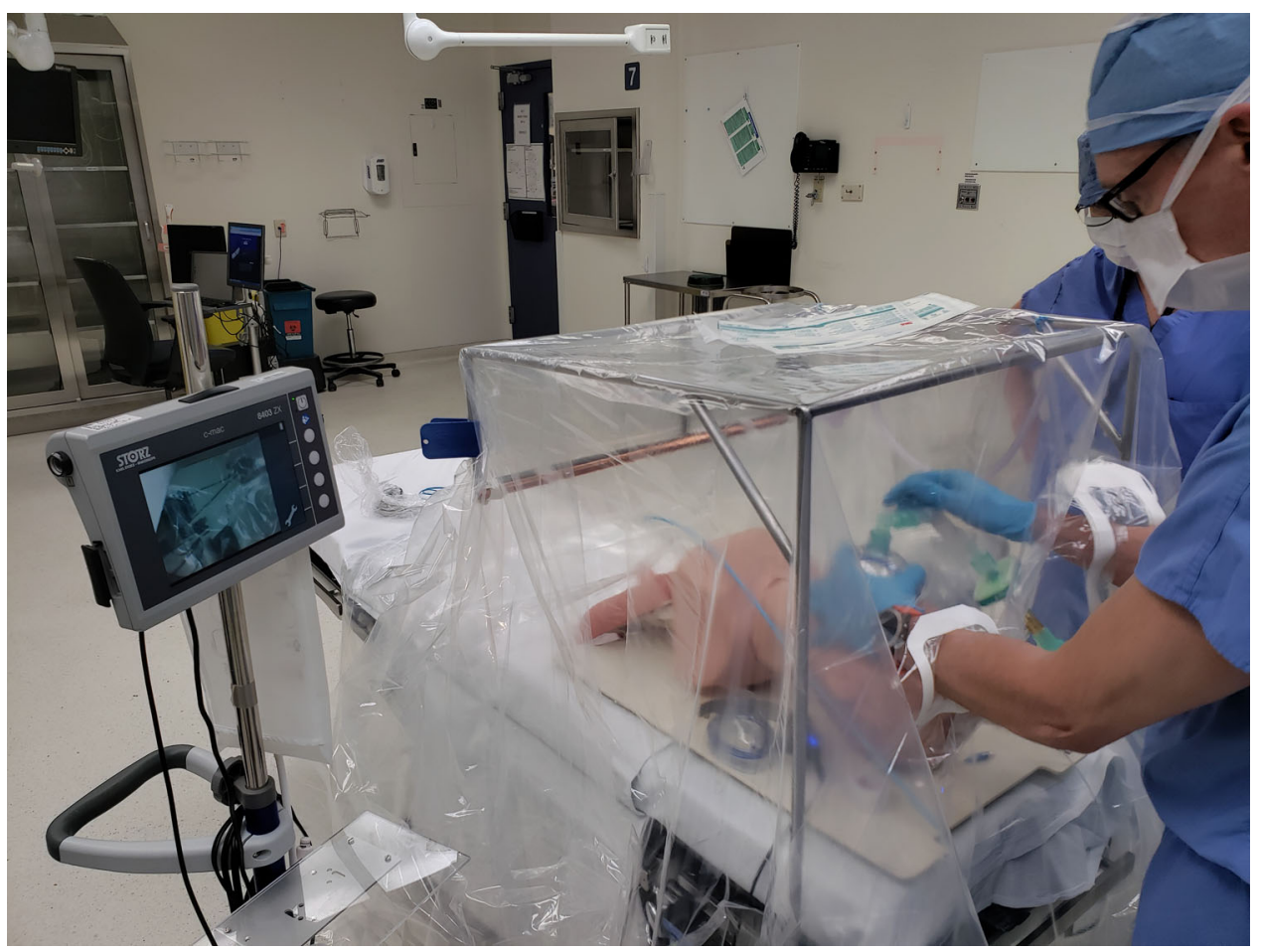

Figure Picture of a prototype COVID-19 airway management enclosure consisting of a stainless steel frame $(0.6 \mathrm{~m}$ high $\times 0.6 \mathrm{~m}$ long x $0.55 \mathrm{~m}$ wide) covered with clear plastic sheeting. The position of the frame over the patient can be adjusted using standard surgical bed rail clamps. A suction source is connected in series to standard anesthesia circuit viral filter (Filta-therm Plus HMEF, Intersurgical Ltd, Berkshire, UK) and manifold pipe at the distal end of the enclosure (filter not visible in picture). The manifold is oriented in front of the patient to draw airflow away from the airway provider. Fresh room air flows from below the bed on each side of the patient in the gap between the bed rail and bed frame. Clear plastic adhesive films (Tegaderm, 3M Canada Inc., London, ON, Canada) were used to cover and re-seal openings cut in the plastic film for the physician's arms to perform airway management. (Note an earlier prototype version is shown in the picture with a $12 \mathrm{~mm}$ copper manifold pipe rather than the manifold pipe used for flow testing. The manifold used for flow rate testing consisted of schedule 40, $19 \mathrm{~mm}$ diameter PVC piping, $0.6 \mathrm{~m}$ long with a linear series of seven holes, $4 \mathrm{~mm}$ in diameter, spaced $50 \mathrm{~mm}$ apart). The number of air changes per hour for the enclosure was calculated using the standard formula: $\mathrm{ACH}=$ flow rate $\left(\mathrm{L} \cdot \mathrm{min}^{-1}\right) /$ enclosed volume $(\mathrm{L}) \times 60 \mathrm{~min} \cdot \mathrm{hr}^{-1}{ }^{4}$. The maximal enclosure volume at full extension $(198 \mathrm{~L})$ was used for the $\mathrm{ACH}$ calculation and the volume reduction due to the patient's upper torso within the enclosure was conservatively omitted from the calculation.
One study measured the time for a $99 \%$ particle count reduction within a COVID-19 barrier hood. ${ }^{3}$ They reported a clearance time of six minutes using a smoke evacuator set at $80 \%$ capacity. Nevertheless, we are unable to directly compare the theoretical and measured clearance times as they did not report their enclosure volume or $\mathrm{ACH}$.

We report the flow rates delivered from common operating room suction sources and employed these values to calculate the $\mathrm{ACH}$ and theoretical aerosol removal times $^{4}$ for a COVID-19 airway management enclosure. In the absence of an accepted standard, we propose that the $\mathrm{CDC}$ calculation for removal of airborne contaminants ${ }^{4}$ from an operating room may be useful in estimating a reasonable "post-aerosol pause" ${ }^{5}$ time period after intubation of a patient using a COVID-19 enclosure. Nevertheless, these calculations assume cessation of the aerosol source and equal distribution of ventilation flow within the enclosed space and may not fully represent a coughing patient. Further investigation into the modelling of flow characteristics within COVID-19 airway enclosures will be critical in refining their performance.

Acknowledgements The authors would like to acknowledge Fossil Power Systems, Dartmouth, NS for fabrication of the initial prototypes.

\section{Conflicts of interest None.}

Funding statement This research study was funded by a Springboard Innovation Mobilization Program Covid-19 Rapid Response Grant.

Editorial responsibility This submission was handled by Dr. Hilary P. Grocott, Editor-in-Chief, Canadian Journal of Anesthesia. 


\section{References}

1. Endersby RV, Ho EC, Spencer AO, Goldstein DH, Schubert E. Barrier devices for reducing aerosol and droplet transmission in COVID-19 patients. Advantages, disadvantages and alternative solutions. Anesth Analg 2020. DOI: https://doi.org/10.1213/ANE. 0000000000004953.

2. Francom CR, Javia LR, Wolter NE, et al. Pediatric laryngoscopy and bronchoscopy during the COVID-19 pandemic: a four-center collaborative protocol to improve safety with perioperative management strategies and creation of a surgical tent with disposable drapes. Int J Pediatr Otorhinolaryngol 2020. DOI: https://doi.org/10.1016/j.ijporl.2020.110059.

3. Shaw KM, Lang AL, Lozano R, Szabo M, Smith S, Wang $J$. Intensive care unit isolation hood decreases risk of aerosolization during noninvasive ventilation with COVID-19. Can J Anesth 2020. DOI: https://doi.org/10.1007/s12630-020-01721-5.
4. Centers for Disease Control and Prevention. Appendix B. Air. - 1. Airborne Contaminant Removal - Table B.1. Air changes/hour $(\mathrm{ACH})$ and time required for airborne-contaminant removal by efficiency. Available from URL: https://www.cdc.gov/ infectioncontrol/guidelines/environmental/appendix/air.html\#tableb1 (accessed June 2020).

5. Wald SH, Arthofer $R$, Semple AK, Bhorik A, Clu AC. Determination of length of time for "post-aerosol pause" for patients under investigation or positive for COVID-19. Anesth Analg 2020. DOI: https://doi.org/10.1213/ANE.0000000000 004921.

Publisher's Note Springer Nature remains neutral with regard to jurisdictional claims in published maps and institutional affiliations. 